\title{
Gloria y ruina de la Iberia Cartaginesa. Imágenes del poder en la historiografía española ${ }^{1}$
}

\author{
Eduardo Ferrer Albelda \\ Universidad de Sevilla
}

\section{Resumen}

Nuestro objetivo es analizar cómo la historiografía española de todos los tiempos ha interpretado el poder -entendido como poder político- ejercido por Cartago en la Península Ibérica, y en concreto por la actuación de los Barca. El tratamiento otorgado hasta bien entrado el siglo XX se basó exclusivamente en la lectura literal de los textos griegos y latinos y, en líneas generales, se puede decir que es una visión profundamente negativa y acrítica, fruto de la comparación con los contextos políticos contemporáneos. Desde mediados del siglo XX, pero sobre todo, a partir de la década de los 80 , el tema entra en una nueva fase interpretativa, teniendo como bases la exégesis de la documentación literaria antigua y el análisis de la documentación arqueológica, contextualizando estos fenómenos en los procesos históricos coetáneos del Mediterráneo.

Palabras clave: Historiografía, Cartago, España antigua.

\begin{abstract}
Our objective is to analyse how Spanish historiography has interpreted political power played out by Carthage in the Iberian Peninsula, in particular through the intervention of the Barca. The approaches to the subject up until the twentieth century has been based on a literal reading of the Greek and Latin texts, and in general has suffered from a negative and uncritical comparison and with contemporary political context. From the middle of the twentieth century and particularly in the eighties, the subject entered a new interpretive phase, taking into account the exegesis of the literary documentation and the analysis of the archaeological record and placing this phenomena in the context of the historic processes of the Mediterranean.
\end{abstract}

Keywords: Historiography, Carthage, Ancient Spain.

\section{INTRODUCCIÓN}

Si pretendemos dotar de globalidad a este análisis, antes de entrar en materia debemos establecer dos fases claramente diferenciadas en la historiografía española plurisecular si tomamos como referencia la metodología historiográfica y las fuentes utilizadas. Hasta fines del siglo XIX, e incluso incluyendo gran parte del siglo XX, toda la producción historiográfica española que había

1 Este trabajo se incluye en el Proyecto Antecedentes y desarrollo económico de la romanización en Andalu- abordado el tema utilizó como única fuente de datos las escasas y controvertidas noticias conservadas en la literatura griega y latina antigua, factor que determinó, como veremos, la interpretación histórica e incluso el juicio moral y la preferencias populares. No obstante, el desarrollo de la ciencia histórica y, en particular, de la Arqueología, así como el despertar de la conciencia epistemológica e historiográfica desde mediados del siglo XX, y en España, a partir de

cía occidental (Ministerio de Educación y Ciencia, DGICYT BHA 2002-0344). 
la década de los ochenta, ha supuesto un cambio radical tanto en los planteamientos de base (las preguntas que se hace el historiador), como en la metodología utilizada para el tratamiento de los datos literarios y arqueológicos, y, lógicamente, en las respuestas emitidas.

Establecida esta cesura entre un período y otro, indispensable para comprender la evolución de la producción historiográfica y los problemas y expectativas que el tema plantea en la actualidad, podríamos señalar, entre otros, tres aspectos que han caracterizado la historiografía española del primer período:

1) Primeramente, podríamos destacar el continuo recurso al presentismo, con toda seguridad y sin el más mínimo espíritu crítico hasta el primer tercio del siglo XX. En la actualidad, y dejando a un lado las tendencias postmodernas más radicales, aunque la disciplina historiográfica y la conciencia crítica ejercen una notable influencia en aras de una mayor objetividad, aportando consciencia de los factores condicionantes (políticos, sociales, académicos, etc.) que actúan sobre el historiador, no por ello dejamos de utilizar una terminología, seleccionar temas y enfocarlos según las circunstancias del presente (Fontana, 1982: 9; Ferrer, 1996a: 15).

Entendemos por presentismo la utilización de modelos interpretativos y la explicación de los hechos históricos tomando como referencia el presente. Se pretende, por tanto, construir el pasado según las construcciones mentales y los factores contextuales coetáneos, argumentando, por ejemplo, superestructuras mentales del pasado y actuales coincidentes, el carácter inmutable de los pueblos a lo largo de la historia, o bien fenómenos pluriseculares (enfrentamientos entre estados civilizados y bárbaros, tópicos raciales, etc.). Los ejemplos en la historiografía española de todos los tiempos son tantos que señalaremos los más característicos cuando revisemos los principales hitos historiográficos.

2) En segundo lugar, otro aspecto importante para describir la imagen del poder en la Iberia cartaginesa es la creación ya en época medieval de un modelo interpretativo casi inmutable derivado de la imagen aportada por la literatura grecolatina. Como ya hemos señalado, desde la historiografía medieval hasta la Guerra Civil española, la única fuente para el estudio de este período fue en la práctica la literatura grecolatina. Las excavaciones de las grandes necrópolis fenicio-púnicas de Ibiza, Cádiz y Villaricos a principios del siglo XX apenas pudieron modificar, a pesar de los intentos (Vives y Escudero 1917;
Mélida, 1929; Ferrer, 1996a: 83-91), un discurso muy arraigado en la producción histórica, si acaso aportaron datos etnográficos y artísticos que ilustraban una interpretación casi canonizada desde los tiempos de Alfonso X.

Por tanto la imagen era deudora casi exclusivamente de las miradas griega y romana, que no eran una ni dos, sino muchas, dependiendo del espíritu de la época y de la filiación del autor antiguo. Como se ha señalado en ocasiones, la historiografía griega y latina no es intrínsecamente anticartaginesa, siendo perfectamente perceptible la diversidad de juicios y la evolución de las fobias y filias despertadas en los autores clásicos (Cássola, 1983; Dubuisson, 1983; Hans, 1991). Por ejemplo, los comentarios de Aristóteles (Pol. II, 11, 1272b-1273a) sobre las instituciones políticas cartaginesas, comparables a las lacedemonias y cretenses, son favorables; la visión de Polibio es pretendidamente objetiva, la de Silo Itálico, Tito Livio o Apiano, profundamente antipúnica, y la de los historiadores tardoantiguos y cristianos, como Orosio, muy negativa (Ferrer 1996a: 19-20). Como ya se ha señalado en relación con la figura de Amílcar Barca, hay una clara evolución en la imagen del cartaginés entre los historiadores romanos, desde la admiración que despierta en autores como Fabio Píctor, Polibio o Catón, hasta el retrato hostil realizado por Apiano (Hans, 1991; G. Wagner, 1999: 264; Lancel, 1997: 42).

No obstante, dado el protagonismo cartaginés y de "españoles" en los conflictos armados de Sicilia y en las Guerras Púnicas, los episodios en los que aparecían más veces retratados y donde fueron derrotados, y teniendo en cuenta que los textos más utilizados mayoritariamente desde la Edad Media fueron los epítomes de autores tardoantiguos y cristianos, especialmente el de Orosio, la historiografía española, salvo excepciones que convenientemente destacaremos, eligió la versión romana más tópica y negativa.

3) Por último, otro pilar fundamental para entender las imágenes emitidas por la tradición literaria española es el concepto mismo de la Historia, de España, y de la historia de España en la tradición historiográfica española. Hasta el siglo XIX, el concepto de historia se debatió entre la idea providencialista cristiana y el concepto cíclico de la historiografía griega, incorporando nociones como la de la sucesión de imperios, a la vez que se establecieron lazos entre la Historia Sagrada y los relatos grecorromanos. En el caso español se parte de una idea de España y de los españoles prístina, siempre existente desde su primera población, y uno de los rasgos más característicos de aquéllos sería la tendencia a la 
desunión, y consecuentemente la propensión a ser invadidos y colonizados, de manera que los cartagineses constituyen un pueblo más en la sucesión de imperios que colonizan a los españoles, idea -la de sucesión de imperios- ya fijada por Eusebio de Cesarea en la Antigüedad Tardía (Catalán, 1982: 16; Orcastegui y Sarasa, 1991: 19). Esta tendencia sería finalmente cercenada con los Reyes Católicos, pero los fenómenos de desunión y las tendencias centrífugas siempre estuvieron latentes, aflorando en épocas de debilidad o crisis (Ferrer, 1996a: 18 ss.).

Contribuirán a esta visión las escasas fuentes conservadas sobre Hispania antigua y sobre la actuación de los cartagineses, de manera que desde la crónica de Alfonso X se propone una ordenación de los hechos, basada fundamentalmente en el epítome de Justino (XLIV, 5, 1-4) y aderezada con los relatos de Vitrubio $(X, 19)$ y Macrobio (Sat. 1, 20, 12), que parte de la fundación fenicia de Cádiz, continúa con la ayuda cartaginesa prestada a esta colonia y la conquista de parte de la provincia, y se afianza en el desembarco de Amílcar en Cádiz. Este es el orden canónico de los sucesos respetado casi hasta la actualidad, y por tanto no deja de ser lógico que una historiografía que tiende al relato cronístico, proponga esta secuencia de sucesos y estime temprana la presencia cartaginesa en suelo hispano.

\section{IMÁGENES ANACRÓNICAS DEL PODER}

Si partimos de la historiografía medieval española como creadora de un modelo interpretativo que perdurará hasta principios del siglo $\mathrm{XX}$, antes debemos hacer notar que la historia antigua de la Península Ibérica, y el tema de la dominación cartaginesa en concreto, no gozó de una especial dedicación a lo largo de este extenso período. El origen de este desinterés se puede atribuir conjuntamente a la escasez de fuentes grecolatinas de primera mano, panorama que no se transformará hasta la segunda mitad del siglo $\mathrm{XV}$ con la conformación de un corpus documental similar al actual; y, por otro lado, a la ausencia de una utilidad ideológica y política de estas historias. Hay mayor interés por vincular los orígenes de las monarquías hispanas, en concreto de la castellana, con los visigodos, que narrar los hechos prerromanos y romanos, que no aportan suficientes argumentos para ensalzarla (Catalán, 1982: 37; Tate, 1970: 20-21).

No obstante, la obra histórica de Alfonso X constituyó una excepción, un prematuro renacimiento clásico, al recobrar la historia previsigoda el espacio y el interés arrebatado por los autores cristianos tardoantiguos y altomedievales. Pero no se trata de una recuperación desinteresada, ya que el proyecto literario del monarca castellano estaba integrado en su ambicioso proyecto político -sus aspiraciones por derechos de sucesión a ceñir la corona del Sacro Imperio Romano-, y por ello recuperó el legado romano en España (Ayerbe-Chaux, 1982: 24; Ferrer 1996a: 22).

Alfonso X elaboró un modelo innovador, continuado y ampliado en sucesivas ocasiones, pero básicamente mantenido hasta el siglo XX, en el que se destacan ante todo los rasgos heroicos de los hispanos. En las ocasiones que le brinda el desarrollo del argumento, la crónica ensalza los valores patrios, con fórmulas que serán desarrolladas en la historiografía posterior, y una de las ocasiones más oportunas será, por ejemplo, la muerte de Asdrúbal a manos de un esclavo, un hombre honrado de España, en palabras del cronista. En definitiva, en la forma y en el fondo, establece un guión repetido y aumentado, reiterado hasta la saciedad posteriormente, que tiene en el género cronístico la forma y en la idea de la existencia en origen de España el fondo.

Hasta el siglo XVI, con la obra de Ocampo, cronista oficial de Carlos I, no se volvió a emprender la tarea de dotar a España de una Historia General, inconclusa hasta la continuación de Ambrosio de Morales. La obra de ambos y la Historia General de Juan de Mariana, de comienzos del siglo XVII, son los referentes de la historiografía nacional hasta mediados del siglo XIX (Wulff Alonso, 1992). La imagen del poder que trasmiten ambas Historias Generales es ciertamente contemporánea a sus autores. Encorsetadas por el género cronístico, precisaron de las invenciones de Annio de Viterbo y de otros falsarios para construir un edificio por completo imaginario descrito casi año a año (Godoy Alcántara, 1868). Como si de los Países Bajos o del reino de Nápoles se tratase, la república ultramarina nombraba gobernadores cartagineses en Andalucía y Baleares, recurriendo a personajes mencionados en la guerras greco-púnicas de Sicilia, como Hannón, Haníbal o Magón, o a personajes ficticios como Boodes o Baucio Capeto. Estos ocupaban sincrónica y reiterativamente el gobierno de estas regiones hasta que eran llamados a combatir en las guerras sicilianas, mientras que los períodos libres entre guerra y guerra se completaban con catástrofes naturales y pestes, al hilo también de las cíclicas epidemias que azotaban Europa. La conquista bárquida y el desarrollo de la segunda Guerra Púnica son descritos con mayor profusión de datos, dado el incremento proporcional de información antigua para estos sucesos, aunque esto no impi- 
dió que se incluyeran relatos fabulosos como las fundaciones de Cartago La Vieja o de Barcelona por Amílcar, el primero de los cuales fue introducido en la historiografía con notable éxito en la bibliografía posterior por el obispo de Gerona Juan Margarit i Pau en su obra Paralipomenon Hispaniae, dedicada a los Reyes Católicos en 1484 (Tate, 1970; Ferrer 1996a: 32).

En líneas generales, los autores de los siglos XVI y XVII como Ocampo, Ambrosio de Morales, Esteban de Garibay, Juan de Mariana o Pellicer de Ossau valoraron la dominación cartaginesa de forma muy negativa, aunque puede apreciarse cierta ambigüedad en el juicio sobre la familia Barca dado el prestigio militar de sus tres miembros más célebres. De un lado pesaba el papel de nación conquistadora y depredadora de los recursos hispanos, o aspectos tan denunciados por la historiografía clásica antipúnica como la crueldad de los sacrificios infantiles o la impiedad, rasgos que contrastaban con la bondad y simplicidad de los naturales. Y si los pasajes grecolatinos no bastaban para otorgar una imagen negativa de los cartagineses, las fábulas introducidas por los falsarios ahondaban más en esta visión, a la par que ofrecían nuevos argumentos para resaltar aspectos positivos de los "españoles" y su integración en los grandes acontecimientos políticos de la Antigüedad. Uno de los pasajes fabulosos más ejemplares en este sentido lo constituye el envío de una embajada española al mando de Marino a la corte de Alejandro Magno en Babilonia para proveerse de protección contra los cartagineses (Mayans i Siscar, 1742: 50-51).

No obstante, a los ojos de estos autores no deja de ser admirable el espíritu de superación que ponen de manifiesto las expediciones oceánicas y las actuaciones de los generales cartagineses, así como la alianza de cartagineses con "andaluces" y saguntinos. Dada la imagen laudatoria y casi apologética con que los Barca eran retratados por los autores hispanos, no es de extrañar que se produjera una hispanización de esta familia, bien a través del matrimonio de los generales con princesas españolas, o incluso atribuyendo un origen expresamente español a Aníbal, que habría nacido en Tricada (isla Conejera, en las Baleares), fruto de la unión entre Saruco, oriundo de la ciudad norteafricana de Barce, y una noble española (sobre la figura de Aníbal, Gala Vela, 1988: 234 ss).

Las fábulas y mentiras no sólo tenían el objetivo de completar los vacíos de la historia de España que las noticias antiguas habían dejado sin cubrir, sino también, de forma interesada, incorporar asuntos que podían llegar a tener un carácter reivindicativo, de derechos históricos, y que expresan perfectamente las preocupaciones sociopolíticas del momento. Dos ejemplos clarificadores: entre las historias falsas se habían introducido dos pasajes que probaban la mayor antigüedad de la presencia de comunidades islámicas y hebreas respecto de las cristianas en España. La llegada de los primeros árabes se atribuía a la presencia cartaginesa, y la de los judíos, que habrían fundado Toledoth (Toledo), se relacionaba con una ficticia venida de Nabuconodosor a la Península Ibérica tras la conquista de Tiro. Lógicamente estas ficciones fueron desenmascaradas ya en el mismo siglo XVII por autores como Bernardo de Alderete o el sevillano Nicolás Antonio.

La impronta del presentismo se deja sentir también en el protagonismo desempeñado en estas historias por reyes, príncipes, gobernadores, señores, un fiel reflejo de la sociedad estamental y de las relaciones políticas de los Siglos de Oro. Los temas históricos que interesan son los hechos políticos y bélicos, en consonancia con el ideal caballeresco que triunfa y que tanto se refleja en la literatura de evasión (Ferrer 1996a: 36). No obstante, esta función legitimadora y apologética de la monarquía y de la sociedad estamental no sólo fue sostenida por las historias generales, sino también por otras producciones en las que el tema cartaginés se vuelve a constituir en el ingrediente idóneo para ensalzar la institución regia y el valor patrio. Un claro ejemplo de lo que decimos es la obra en verso de Pellicer de Ossau titulada Orisson el Grande, Monarca de las Españas, con la muerte de Amilcar Emperador de los Cartagineses, publicada en 1666.

\section{LABORES DE HIGIENE EN LA HISTORIO- GRAFÍA ESPAÑOLA}

Esta concepción de la historia empieza a ser cuestionada en la segunda mitad del siglo XVII, no sin resistencias y sin un triunfo claro de un modelo alternativo. El criticismo y la erudición serán los motores de las transformaciones, inexplicables sin un cambio en las mentalidades. A lo largo de la primera mitad del siglo XVIII se produce el enfrentamiento entre dos maneras de entender la historia y dos formas contrapuestas de amor a la patria. En la postura reformadora se intentan desterrar todas las historias falsas, no documentadas, precisamente por prestigio patrio, para desterrar todas aquellas historias ficticias que causaban del desprestigio de España entre el resto de las naciones europeas. Contrariamente, el nacionalismo más reaccionario se apoyaba en las mismas fábulas para desta- 
car valores y rasgos de identificación patrios (Ferrer 1996a: 52-53).

Con precedentes inesperados, como Bernardo de Alderete, canónigo de la catedral de Córdoba de comienzos del setecientos, la labor de limpieza de las historias nacionales mediante el criticismo y la erudición tendrá como valedores a autores como Nicolás Antonio o Gaspar Ibáñez de Segovia en el último tercio del siglo XVII. Su principal cometido será el de desterrar de la historia de España todas las leyendas y ficciones que la historiografía tardomedieval y renacentista había introducido, imaginadas por Annio de Viterbo y por otros falsarios, y transmitidas sin mucho convencimiento pero con éxito por Ocampo y Mariana, hasta instalarse de manera permanente en las historias oficiales. La labor de estos autores consistirá básicamente en someter a una profunda revisión las fuentes literarias, separando las antiguas de las falsas y advenedizas, y de esta manera se desmontaron no pocos episodios y protagonistas inventados.

Esto supuso, entre otras consecuencias, una considerable merma en el repertorio de fuentes y la formación de un corpus cuantitativamente similar al actual, lo que desencadenó a su vez la superación del género cronístico que había caracterizado la producción historiográfica desde la Primera Crónica General de Alfonso X. Hasta mediados del siglo XIX no se emprenderá la tarea de escribir una nueva Historia General de España, ahora en versión liberal, fundamentalmente porque la demanda había quedado satisfecha con la obra de Mariana. No obstante, y a pesar de los esfuerzos invertidos por el criticismo, el modelo erudito e ilustrado no acabó de imponerse -muchas obras ni siquiera se editaron-, y ambas corrientes discurrieron en paralelo.

Además del saneamiento de las fuentes, un aspecto destacable de la historiografía dieciochesca fue la sustitución del sujeto de la historia (Maravall, 1972: 250 ss.). En siglos anteriores el cultivo de la disciplina se había dedicado a la vida y milagros de reyes, príncipes y capitanes, apostando por una concepción aristocrática y didáctica de la historia, que otorgaba el protagonismo del acontecer a la realeza y a la nobleza, por lo que adquiría la función de manual de comportamiento donde los gobernantes podían aprender y mirarse (Cabrera de Córdoba, 1611: 5-6). Al contrario, la historia ilustrada fue fundamentalmente antiheroica (Mestre Sanchís, 1988: 333), y sus objetivos, como explica el ilustrado Forner (1816), no serán "las proezas y hazañas de los héroes y guerreros... bastante ensalzadas en millares de tomos; falta representar la vida polí- tica, y ver en los tiempos antiguos los orígenes de lo que hoy somos, y en la sucesión de los tiempos los progresos no de los hombres en individuo, sino de las clases que forman en cuerpo social”. La política, la economía, la moral y las costumbres, la religión, serán ahora los objetos de estudio de la historia, y sus protagonistas los grupos "civiles" (Ferrer, 1996a: 55-56).

Sin embargo, ni la erudición ni el criticismo pudieron prevenir ni eliminar la tendencia a usar y abusar de la historia, de manera que la producción dieciochesca no sólo no estuvo ajena a esta propensión sino que presentó síntomas evidentes de continuidad con la historiografía de los siglos XVI y XVII, fundamentalmente en la aceptación del modelo interpretativo básico de la unidad original de España y en la reiteración de la existencia de rasgos inmutables de lo "español": virtudes como la constancia, el valor, la industriosidad, y defectos como la tendencia a la desunión que favorecerá las sucesivas invasiones e intervenciones extranjeras (Cruz Andreotti y Wulff, 1992: 165; Ferrer, 1996a: 56).

No obstante, merece una especial atención la radical transformación de la historiografía ilustrada en el juicio histórico positivo de la aportación cartaginesa en la configuración de la cultura española. Por ejemplo, la obra de los hermanos Rodríguez Mohedano, Historia Literaria de España, consigue zafarse de los prejuicios que lastraban la civilización púnica en su globalidad, pues juzgaron tendencioso el retrato que los historiadores romanos hicieron de ésta. En contraste con la imagen depredadora que los cartagineses habían adquirido durante siglos, los ilustrados españoles alabaron las altas cotas de desarrollo científico y cultural alcanzadas por aquellos. La valoración positiva de las aportaciones cartaginesas a la cultura hispana es de tal magnitud que los RR.PP. Rodríguez Mohedano (1776: 277) llegan a afirmar que "la cultura cartaginesa es origen de la española".

Los hechos históricos que destacan son los reclutamientos de tropas españolas con anterioridad a las guerras de Sicilia y el establecimiento de colonias cartaginesas en Ibiza y en Iberia, que van a ser determinantes en la prosperidad de Cartago. El aparato crítico no es obstáculo para que domine, como en la obra de Masdeu (1785), un espíritu apologético y patriótico, de loa continua a los valores patrios. Estos ilustrados estaban al tanto del bajo concepto que de España y de la cultura española existía entre los países europeos, y sus obras pueden ser consideradas réplicas a este menosprecio (Mestre Sanchís, 1988: 339 ss; Moreno Alonso, 1979: 152). Por ello mantienen intactos episodios e interpretaciones no por 
repetidas menos útiles para el elogio al genio español: descripción de las riquezas naturales, muertes de Amílcar y Asdrúbal a manos de españoles (Martín de Ulloa, 1796: 101), matrimonios de los Barca con princesas españolas, o la intervención de hispanos en episodios internacionales como la ayuda de los "españoles" a Tiro ante el asedio de Nabuconodosor (Ortiz y Sanz, 1795: 910), las guerras de Sicilia, donde demostraron su valía en el combate, o la embajada de los hispanos a la corte babilónica de Alejandro Magno, que "muestra que por este tiempo eran ya una Nación culta, y hacían singular aprecio de la gloria militar" (Rodríguez Mohedano, 1766: 318).

En las historias dieciochescas se aboga por la relación de reciprocidad en las relaciones hispano-púnicas: España integraba a los cartagineses y los hacía españoles, participando de una cultura superior a cambio de riquezas y soldados, que son los que originan a su vez el engrandecimiento de Cartago. Hay una recepción asentida de ideas foráneas y un enriquecimiento cultural y material recíproco: si los Barca son los que enseñaron el arte militar a los españoles, los cartagineses aprendieron de los gaditanos la pesca del atún (Ferrer, 1996a: 61).

De todas formas, la elección del ingrediente fenicio-púnico como germen de la cultura española no era tampoco una decisión desinteresada, pues con ello se pretendía establecer rasgos diferenciadores entre España y otras naciones europeas que no habían experimentado, ni "gozado", de la conquista y colonización fenicio-púnica, como por ejemplo Francia, escorada en la búsqueda de su origen cultural hacia el helenismo por la fundación de Massalia en su solar patrio (Cruz Andreotti y Wulff, 1992: 171).

\section{Pérfida Cartago}

La versión ilustrada de la España cartaginesa, sin embargo, no fue aceptada ni siquiera minoritariamente por sus contemporáneos ni por la historiografía romántica decimonónica. De los esfuerzos del criticismo y de la erudición dieciochesca sólo se preservó la eliminación definitiva de los falsos cronicones y los pasajes míticos, pero se había dejado la puerta abierta a la subjetividad. Bien es verdad que la Antigüedad, y en concreto la presencia cartaginesa en la Península Ibérica, tampoco fueron materias de interés para una historiografía enfocada hacia los períodos medieval y contemporáneo, que eran los que ofrecían más episodios y pretextos para el ensaljamiento de la ideología liberal de época isabelina (Cirujano y otros, 1985: 56-59). Pero las veces en que fue abordado el tema, especialmente en las historias nacionales, la consideración fue siempre profundamente negativa.

Un aspecto de interés con respecto a la imagen del poder en la historiografía romántica es el cambio de sujeto de la historia. Enlazando con la bibliografía ilustrada, la ideología liberal se deshizo de los protagonistas de antaño, príncipes, capitanes y nobles que aún pervivían en la reeditada obra de Mariana, y los sustituyó por los acontecimientos colectivos, en los que el pueblo, y junto a él la monarquía, se constituían en los ejes del acontecer histórico (Cirujano y otros, 1985: 17).

La noción de una España prístina, inmutable en la conformación del carácter y genio de su población, estuvo tan presente como antes, a la vez que la idea del solar patrio como escenario de invasiones favorecidas por la tendencia a la desunión y a las luchas civiles, en la que intervino sin duda el trauma de la invasión napoleónica y las guerras carlistas. Los españoles eran "indóciles, indomables, incapaces de unirse y de constituir un cuerpo sólido y vigoroso, la imprevisión y el espíritu de independencia (los) caracterizaba... Apegados a su país nativo no tenían ese genio vagante y emprendedor propio de otras tribus bárbaras... El único sentimiento común que ligaba á los españoles era el odio a los extranjeros y el deseo inextinguible de sacudir su yugo... y eran también, como todos los pueblos poco cultos, hospitalarios y benéficos" (Morales 1838: 350-351).

A los ojos de un autor de época isabelina "la historia de España presenta un fenómeno que debe detenidamente considerarse. Miles de causas favorables a la civilización, y miles de causas contrarias se han disputado continuamente el campo; y ni las unas han conseguido consolidar un buen gobierno y desenvolver del todo la ilustración, ni las otras sumirnos en la barbarie. El ingenio español lozano, independiente, vigoroso y siempre ligado, llegó á perder hasta los deseos de salir de la esclavitud, y solo daba muestras de su pujanza por el brío con que conmovía sus cadenas". El autor se pregunta por la causa de estas peculiaridades y no halla otra respuesta que el determinismo geográfico: "debe haber en nuestro suelo, en nuestro clima, en nuestros alimentos alguna causa que imprime á nuestro carácter ese sello de originalidad distintivo de la raza española” (Morales, 1838: 349-350). Décadas después A. Cavanilles (1860: 15-179), autor de una Historia de España, consideraba a los "españoles" de la época de Estrabón idénticos en sus rasgos característicos a los hispanos coetáneos: "sobrios, pródigos de la vida, que preferían la muerte a la deshonra, que vivían aislados en sus 
distintas regiones, que eran celosos de su independencia...".

En el siglo XIX se fragua la imagen radical y apasionadamente negativa de la presencia cartaginesa en suelo ibérico, siempre definida en términos de tiranía y de rapacidad. Los cartagineses fueron conquistadores, invasores ávidos de explotar las riquezas naturales de España, no aportaron cultura e implantaron un régimen tiránico; tan sólo la figura de Aníbal admitía comentarios favorables por su genio militar. En consecuencia los historiadores no ahorraron epítetos de desprecio: pueblo "lleno de ambición y de codicia, menospreciador de la fe y palabra empeñada" (Cavanilles, 1860: 21); se distinguía de los españoles "por su ardor guerrero, por una inquietud belicosa que los conducía, no solo a sostener por las armas sus establecimientos, sino a atacar sin piedad a cuantos a su engrandecimiento se opusieran" (Lafuente, 1850: 321); "pueblo sin corazón, aleve y codicioso", "soberbia Cartago", "con insaciable sed de lucro", una "República codiciosa y egoísta, sin fe, o con una fe de recuerdo imperecedero en la historia". En definitiva "fue más extranjera en España que otro alguno de los pueblos que han dominado la Península... A diferencia de los fenicios, pueblo religioso, leal, pacífico y comerciante de buena fe" (Guichot, 1869: 38-57).

Esta es la visión que domina la historiografía romántica, y en general la decimonónica, perpetuada hasta bien entrado el siglo XX gracias a la obra de Schulten. Tomada ésta como chivo expiatorio al ser considerada generadora de no pocos males de la historiografía española del siglo XX, no obstante la versión schulteniana de la actuación cartaginesa en España no era, ni en la forma ni en el fondo, original, y todos los hitos de su peculiar interpretación estaban representados ya hacía años en la bibliografía española: la destrucción de Tartessos por Cartago, la política de bloques antagónicos entre bárbaros y helenos, el "destino manifiesto"del enfrentamiento entre púnicos y romanos, la comparación de Cartago y Gran Bretaña (Vives y Escudero, 1917: V), etc.

No nos resistimos a trasladar literalmente algunos pasajes escogidos con tal fin. "Aún no mediado el siglo VI a. de J.C., pudo ya observarse que se había creado para el reino tartesio una situación por todo extremo peligrosa con la helenización de la bahía de Cádiz. Insensiblemente, el gobierno político del Estado había venido a ser patrimonio de los grandes potentados del Puerto y de la Isla, raza bastarda, en quien se había juntado tres distintas sangres, semítica, turania y arya, y cuya refinada cultura y tendencias progresivas y cosmopolitas hacían que se considerase de condición superior a la masa del pueblo, compuesta de los verdaderos tartesios". Tras la muerte de Argantonio, esta situación de injusticia originó la revuelta de los tartesios contra Cádiz y la intervención de Cartago. "Tengo por verosímil que los tartesios no pelearon solos en esta guerra; que hubieron encontrado aliados en alguna parte de las naciones marítimas del Mediterráneo. Añado más; un aliado así, apenas podía venir de otra parte que de las Baleares. Tal hubo de ser Therón, "rey de la España citerior", a quien Macrobio nos presenta bloqueando,..., la parte occidental de la isla de Cádiz...". "Arrasada la ciudad de Tarteso... todas las glorias de aquella se transfirieron a ésta" (Costa, 1891-1895: 93-98).

Para M. Lafuente (1850: 322), el episodio de la ayuda cartaginesa a Cádiz finalizó, como no podía ser de otra manera, con una traición: "Miras no menos avanzadas ni mas generosas traían respecto a los fenicios en cuyo auxilio acudieran. Llevados del pensamiento, propio de corazones desleales, de expulsar de la Península aquellos mismos a quienes debían el pisar la tierra de España, a aquellos mismos hermanos que los habían invocado por auxiliadores, ..., acometieron su principal ciudad y atacaron a Cádiz con el interés y empeño de quienes parecía mirar su conquista como la base del futuro señorío de toda España, que ya entonces sin duda entraba en sus proyectos y designios".

"La intervención armada de los cartagineses se convirtió pronto en dominación, absorbiendo a las antiguas colonias fenicias de España y obligándolas a depender directamente de Cartago. Apoyada esta ciudad en sus nuevos dominios, continuó sus luchas con los griegos... En estas luchas, destruyeron algunas colonias foceas, como la de Mainake... Para asegurar su dominación, implantaron los cartagineses en España el régimen que usaban en África, más militar y opresor que el de los fenicios. Pusieron guarniciones en las ciudades principales, trajeron colonos y trabajadores de la Libia, y sujetaron fuertemente a muchas tribus españolas con tributos en dinero y servicios." (Altamira, 1909: 31 y 87).

"Llegaron a monopolizar el comercio marítimo con los extranjeros y con sus propias colonias, en términos, que hubieran dado celos a la mismas Inglaterra del tiempo de Cromwel, cuya famosa Acta de navegación, parece haber sido calcada sobre los reglamentos marítimos de Cartago" (Guichot, 1869: 36).

(Cartago y Roma) "crecieron para ser rivales, para empeñarse en contiendas que tuviesen por objeto la exclusiva dominación del mundo; ... 
empeñaron su lucha a muerte, que solo podía terminar con la destrucción de uno de los imperios (Cavanilles, 1860: 21).

Estas versiones no se diferencian sustancialmente de la que años después ofreciera Schulten (1922 y 1924a y b), aunque la del autor alemán estuviera indiscutiblemente más elaborada. Para el catedrático de Erlangen, la actuación cartaginesa en España está ligada, por lo menos en sus orígenes, a la existencia y destrucción de Tartessos y de sus aliados focenses. La relación entre tartesios y cartagineses está planteada como una dinámica de bloques o lucha entre potencias, y ello es debido a que inciden en Schulten determinadas concepciones historiográficas que, como señalan algunos autores, presuponen tanto el carácter natural de los enfrentamientos entre estados, como el que dichos enfrentamientos sean incluso de índole ética (Cruz Andreotti, 1987 y 1991; Sánchez y Cruz Andreotti, 1988: 34; Olmos, 1991). Esta política de bloques estaría protagonizada por pueblos de origen egeo, atenienses, tartesios y focenses, en el bando civilizado, secularmente en litigio contra los bárbaros (persas, etruscos, cartagineses) por el dominio del mundo, entrando en fricción dos universos contrapuestos, la civilización contra la barbarie (Ferrer 1996a: 94).

El hecho de que unos pocos años antes Schulten (1920) hubiera ofrecido una visión menos apasionada en su obra Hispania, en la que todavía no aparecen claramente delimitadas las bases de su interpretación posterior, como la política de bloques, o la destrucción de Tartessos por Cartago, puede ser un indicio de que la visión posterior estuviera mediatizada por el final de la primera Guerra Mundial y por el tratado de Versalles. Este es precisamente uno de los rasgos que mejor caracterizan la obra de Schulten, la integración del historiador en un momento político, esto es, el presentismo. "El trauma de la primera Guerra Mundial hunde a Alemania en una crisis de valores que intentan reafirmar buscando modelos en pueblos sin pasado imperialista, encontrándolo en Tartessos, que identifica subconscientemente con Alemania, mientras el papel de Cartago lo interpreta el Reino Unido" (Sánchez y Cruz Andreotti, 1988: 34-35; Ferrer 1996a: 95).

La identificación entre Cartago e Inglaterra era moneda de cambio en la época pues ambas potencias, una en la Antigüedad y la otras en los tiempos modernos, fueron señoras de los mares; no obstante, Schulten llevó la comparación hasta el extremo, compaginando pasado y presente sin distinción, y proponiendo una trilogía de episodios bélicos de repercusión mundial en los que se midieron estados civilizados y bárbaros: la destrucción de Tartesso y Mainake en Occidente, que inauguró la milenaria secuencia de guerras entre civilizaciones, las guerras del Peloponeso y la primera Guerra Mundial. Esta la última "provino del celo que Inglaterra y sus aliados sentían de Alemania, que estaba ganando pacíficamente el mundo para su comercio. Así se nos muestra la envidia como un resorte poderoso para el hombre, siendo causa de las tres mayores guerras" (Schulten, 1924b: 15).

\section{FENICIOS Y CARTAGINESES EN OCCIDENTE}

Con un retrato así esbozado, no podemos calificar de otro modo que de revolucionaria la imagen y, sobre todo, la metodología, que aportara García y Bellido (1942a y b; 1952) en su obra dedicada a Fenicios y Cartagineses en Occidente. Revolucionaria en el método porque es el primer autor que de manera sistemática utilizó los datos arqueológicos para construir la historia, sin supeditarlos al guión fraguado durante siglos por la tradición anterior y vagamente intuido en los textos clásicos. Con escasos precedentes en la bibliografía hispana, consiguió ordenar y publicar todos los hallazgos fenicio-púnicos de la Península Ibérica y de Ibiza, sobre todo funerarios, y los convirtió en una fuente da datos demográficos, económicos, religiosos y artísticos. Elaboró, pues, el primer corpus completo de la cultura material fenicio-púnica (García y Bellido, 1952: 337 ss.).

En segundo lugar, su obra es revolucionaria porque, desmarcándose del historicismo postromántico de Schulten y de la rancia tradición decimonónica española, fue capaz de desideologizar la historia antigua (Arce, 1991: 209-211), y sobre todo un tema que, junto con otros, había constituido la columna vertebral de la interpretación historicista. En lo que no hubo modificación fue en la concepción, prístina, eterna y universal de España, de la españolidad y de los españoles, fenómeno hasta cierto punto lógico si analizamos el período de producción del autor, incluido íntegramente en la era franquista.

A pesar de ello, la imagen de los cartagineses se modificó sustancialmente, desapareciendo ciertos componentes negativos derivados de planteamientos racistas propios del evolucionismo que se habían impuesto en el primer tercio del siglo XX. Las razas llevaban aparejadas determinadas cualidades y defectos, y la semita, y más concretamente la cartaginesa, no era la más afortunada, pues a ella se le atribuía la condición natural del oportunismo, la avaricia, la doblez y la falta de palabra. Asimismo, la titáni- 
ca lucha entre culturas, entre la civilización y la barbarie que desde la historiografía griega hasta el momento había presidido el discurso historiográfico, es pensada como una lucha por la hegemonía comercial entre cartagineses y massaliotas. En este contexto político, deja de tener sentido para García y Bellido la supuesta destrucción cartaginesa de Tartessos que había inspirado el epítome de Justino, y el final trágico se sustituye por una decadencia económica que la competencia comercial foceo-cartaginesa provocó. Argantonio, tantas veces alabado por la historiografía española de todos los tiempos, sin embargo es caracterizado como un antipúnico oportunista (García y Bellido, 1942a: 35; Ferrer, 1996a: 104).

\section{LAS DOS ÚlTIMAS DÉCADAS}

La ordenación de los textos literarios grecolatinos realizada por Schulten y la obra de García y Bellido fueron consideradas durante décadas definitivas, y el panorama no va a cambiar prácticamente en cuarenta años. En este dilatado período tan solo algunas publicaciones de Blanco (1967: 167 ss.) y Blázquez (1980: 415 ss.) van a retomar el tema, si bien seguirán fieles en la forma y en el fondo a la obra de García y Bellido. Un aspecto que surge ahora y que nos interesa destacar por su vinculación con la imagen del poder es la hipotética identificación de los tipos monetales hispano-cartagineses con los retratos bárcidas, a la manera helenística. Este es un aspecto no menor porque se pretende demostrar con ello, apoyándose en dos pasos de Polibio (3, $8,1 ; 10,10,9)$, la actuación de los bárcidas en Iberia como auténticos monarcas helenísticos, siendo la emisión de moneda con sus retratos una manifestación más de esta expresión de poder (Blázquez, 1976).

A principios de los años 80 se abren nuevas perspectivas y, en nuestra opinión, asistimos al cambio más radical experimentado en el tema concreto de los cartagineses en la historiografía española. No sólo se trata de un cambio apreciable en las conclusiones históricas, que lo es, si no sobre todo en la metodología empleada, en el tratamiento de la documentación literaria y arqueológica. Por un lado, los textos, al menos desde el punto de vista teórico, ya no deben ser interpretados literalmente sin haber sido sometidos antes a una exégesis y a una labor crítica que abarque aspectos como el análisis del autor, la trasmisión de los textos, el género literario al que pertenece, etc. En lo que se refiere a la documentación arqueológica, el registro ya no sólo servirá como mera ilustración de lo que los tex- tos apuntan, sino que se les otorgará una capacidad autónoma y complementaria, nunca subsidiaria, para construir historia.

Esta es, a nuestro juicio, una transformación que no dudamos en calificar de trascendente, y que lógicamente ha contribuido a introducir notables cambios en las conclusiones históricas, a pesar de que en estas décadas el tema de la presencia cartaginesa en Iberia ha estado en condiciones de desigualdad en lo que a la atención de los investigadores se refiere, pues la producción es mínima si la comparamos con otros aspectos de la protohistoria surpeninsular como la colonización fenicia o la cultura tartésica.

El contraste con la historiografía anterior es evidente: los autores ya no hablarán de España, sino de la Península Ibérica, como una entidad geográfica, no política. Este cambio de nomenclatura es más significativo de lo que en un principio pudiera parecer, pues toda la carga ideológica acumulada desde la Edad Media hasta la postguerra española desaparecerá; se renuncia expresamente a la idea de una España sempiterna, a los tópicos sobre las tendencias seculares centrípetas y centrífugas de España durante la Antigüedad, y a la inmutabilidad de la racialidad y del "carácter español" desde la Antigüedad hasta el presente. A la vez, se abandona el paradigma invasionista, la tendencia crónica a ser invadidos, en favor de unas tesis mucho más matizadas sobre los fenómenos de colonización e interacción, ocupando los indígenas un lugar activo y preferente, no meramente pasivo, en el proceso histórico.

Consecuentemente, las imágenes del poder emanadas de ambas concepciones van a desaparecer al mismo ritmo. Al desacreditarse el fin violento de Tartessos a manos cartaginesas y el fenómeno invasionista, se cuestiona por primera vez y por parte de un sector importante de la investigación la presencia cartaginesa en la Península Ibérica en la época anterior a la conquista bárquida. Es ahora cuando surge el concepto de hegemonía frente al de imperialismo (González Wagner, 1983; 1984; 1985 y 1989; Barceló, 1988; López Castro, 1991a y b; 1994).

No queremos plantear el análisis historiográfico de los últimos 20 años como una enumeración de autores y temas y la crítica de ambos, sino más bien exponer cuál es el momento historiográfico en el que nos encontramos y cuáles son los avances y los desafíos de la investigación. Nos obstante creo que es de justicia señalar el hecho de que fue la Tesis Doctoral de González Wagner (1983) la que generó esta inflexión en la tendencia continuista de la historiografía hispana, ade- 
más de ser el origen en España de una corriente interpretativa sobre la actuación cartaginesa que hoy goza de una gran aceptación.

De esta nueva fase historiográfica destacamos los siguientes aspectos:

1) En primer lugar, el que nos parece más trascendente, ya que conlleva otros fenómenos aparejados, es la integración definitiva de Iberia en el contexto del Mediterráneo. El aislamiento político y cultural de España en las dos últimas centurias había originado un ensimismamiento, una sensación de excepcionalidad, las más de las veces negativa, que hacía comprender a la Península Ibérica como un territorio ajeno al proceso histórico mediterráneo. Los cambios sociopolíticos a partir de los años 70, y sobre todo en los 80, desactivaron esta tendencia secular y lógicamente tuvo su inmediata repercusión en la historiografía. No obstante, no por ello hemos dejado de ser conscientes del lugar periférico que Iberia ocupó en relación con las áreas más dinámicas del Mediterráneo oriental, hablando siempre desde el punto de vista de un espectador oriental. En este sentido el Extremo Occidente, como se denomina habitualmente a la Península Ibérica, se fue integrando poco a poco en la dinámica mediterránea, lo cual se percibe de manera clara en la literatura griega (Cruz Andeotti, 1995; Ferrer, 1996b; Ciprés y Cruz Andreotti, 1997); y este proceso de integración lo hará en gran medida de la mano de Cartago (Bendala, 1987 y 1994).

Pero para el espectador occidental, el Extremo Occidente tiene su propia dinámica histórica, la cual ya no va a depender en su investigación ni en su redacción de la historiografía griega ni de la latina, las transmisoras de los datos textuales que se conservan en la actualidad, ni tampoco de la cartaginesa, sino que dispone de una fuente de datos, fundamentalmente arqueológicos, que hacen posible a partir de diversos enfoques teóricos la construcción de una historia extremo-occidental propia (Arteaga, 1994: 23-25).

2) En segundo lugar, un aspecto no menos importante es la diferenciación progresiva, hoy plenamente aceptada, entre las comunidades púnicas, o fenicias occidentales si se prefiere (López Castro, 1991a y b; 1992; 1995), y Cartago, no sólo en la esfera política, aspecto éste muy matizable, sino sobre todo en su etnogénesis y en su cultura material. Me explico: las comunidades púnicas son consideradas, desde el punto de vista poblacional, el resultado de la evolución demográfica de las colonias fenicias y de los procesos de mestizaje con las poblaciones indígenas, y no de las aportaciones poblacionales de origen norteafricano, libio o cartaginés. Estas poblaciones serán denominadas por los autores grecolatinos antes y después de la conquista romana con los etnónimos mastieno y bástulo respectivamente (Ferrer 1996a y b; 1998; 2000; 2004; Ferrer y Prados, 2001-2002).

La noción de una colonización cartaginesa y de una política colonial en Iberia por parte de la metrópoli norteafricana, a excepción de aspectos muy concretos, no tiene hoy la menor vigencia. Al contrario, uno de los fenómenos pre-helenísticos más destacados fue sin duda la emergencia de poléis púnicas ya conformadas plenamente a fines del siglo VI a.C., o sea de comunidades más o menos independientes, con un territorio y formas de gobierno propias (Artega, 1990; Ferrer, 1998; López Castro y Mora, 2002). En el terreno de la hipótesis, se ha propuesto la formación de ligas o confederaciones políticas, como la que se atribuye a Gadir en relación con el Círculo del Estrecho (Artega, 1994 y 2001). La culminación de este largo proceso de integración sería la conquista bárquida, la segunda Guerra Púnica y la victoria romana, y con ellos el abandono de su "identidad periférica" y la incorporación definitiva de Iberia en el mundo mediterráneo antiguo.

3) Otro aspecto aparejado al anterior que ha capitalizado gran parte de los activos de la investigación, es el de la relación política entre las comunidades púnicas de Iberia y entre éstas y Cartago. Hay acusadas divergencias en la interpretación, que oscilan entre la sumisión de las antiguas colonias fenicias a Cartago (Bendala, 1987; Frutos 1991 y 1993), la hegemonía de la ciudad norteafricana sobre el litoral mediterráneo que se irá transformando paulatinamente en dependencia (González Wagner, 1983, 1985, 1989 y 1994), o el liderazgo ejercido por Gadir sobre las comunidades púnicas occidentales mediante la formación de ligas político-religiosas, en pie de igualdad con Cartago (Arteaga 1994 y 2001); e, incluso, la formación de comunidades púnicas (mastienas/bástulas) que no constituyen un bloque homogéneo desde el punto de vista de las relaciones políticas, pues algunas de ellas, las más orientales, estuvieron vinculadas a Cartago tempranamente, mientras que otras lo estuvieron con Gadir o fueron completamente autónomas. A esta consideración de orden espacial habría que añadir otra temporal, pues las relaciones políticas no permanecieron estables a lo largo de estas centurias, sino que hubo, sobre todo a partir del siglo IV a.C., un incremento de la dependencia política del Extremo Occidente con respecto a Cartago (Ferrer, 1998). 
La interpretación sobre el imperialismo cartaginés que introdujera González Wagner (1983; 1985 y 1989) en nuestras historias, proviene del análisis de Whittaker (1978) sobre la actuación cartaginesa en Sicilia, que propone la ausencia de una política imperialista cartaginesa, de conquista territorial, previa al siglo III a.C. Aplicado este modelo a Iberia, las comunidades púnicas evolucionarían desde una situación de relativa autonomía bajo la hegemonía de Cartago, en la que el comercio administrado es el vehículo de aplicación de esta política, hasta una situación de mayor dependencia que culminaría con la anexión territorial.

Hoy por hoy es la interpretación más aceptada, de tal forma que, hace una década, en una revisión historiográfica sobre Cartago y la Península Ibérica, López Castro (1994: 528) daba por cerrado el debate sobre la política imperialista cartaginesa en la Península Ibérica anterior a los bárquidas, y manifestaba con optimismo que "las nuevas teorías y modelos generados en los 80 han de orientar..., la investigación futura: en los próximos años deberá a ser encaminada a desarrollar y mejorar el modelo de relaciones entre Cartago y la Península Ibérica establecido en los 80, integrando la importante documentación arqueológica producida en los últimos 15 años".

Sin embargo, la investigación futura, o sea la actual, no ha enterrado bien el debate y ha renacido con fuerza la idea una intervención activa cartaginesa en la Península Ibérica con anterioridad al desembarco de Amílcar Barca. Véase a tal efecto las recientes aportaciones de Koch (2002: 190 ss.) y López Pardo (2002: 113 ss.), o los interesantísimos datos proporcionados por R. Pliego (2001; 2003 y e.p.) sobre un campamento cartaginés de finales del siglo IV o principios del III a.C. en el área turdetana, cercana a Carmo, relacionados por la autora con la estrategia de captación de mercenarios, lo que, como es lógico, conllevaría un dominio territorial.

4) Pero no queremos que este debate capitalice el tema. Otra característica que destacaríamos en esta nueva fase historiográfica es la ampliación y la diversificación de los estudios sobre las comunidades púnicas, sobre todo en lo que se refiere a una nueva manera de leer y entender el registro arqueológico, produciéndose avances notables, que sin ser espectaculares, han transformado la investigación de manera considerable. Ya no sólo interesa la historia política o la exégesis de los escasos textos conservados (Ferrer, 1996b); los estudios sobre territorio, economía, singularmente sobre la producción y comercialización de salazones y salsas saladas de pescado, también sobre agricultura, yacimientos concretos, numismática, religiosidad y costumbre funerarias, iconografía, repertorios cerámicos, etc., están resueltos acabar con la secular ausencia de contenido arqueográfico de esta cultura y la atonía de esta fase cronológica (Ferrer, 1995; Martín Ruiz, 1995). El lapso de tiempo que Annio de Viterbo, Ocampo y Mariana colmaron de ficticios gobernadores cartagineses, los investigadores actuales lo historiamos con ánforas, tumbas, santuarios, monedas y dispersión de yacimientos en un territorio.

Un último aspecto en el que queremos incidir, y que es precisamente el que nos convoca en esta monografía, es una línea abierta y desarrollada por autores como Blázquez (1991), Bendala (1987 y 1994) y González Wagner (1999), cual es la introducción de ideologías y formas helenísticas en Iberia a través de la actuación bárquida. Como ya señalamos supra, creemos que el Extremo Occidente no se mantuvo al margen ni ajeno a los principales procesos históricos en la época postcolonial, pero coincidimos con estos autores en que la corta dominación cartaginesa y sus consecuencias constituyeron el factor definitivo de la integración de parte de Iberia en las relaciones panmediterráneas.

En las centurias que median entre fines del siglo VI y 237 a.C. hay numerosas evidencias de estas relaciones, debidas sobre todo a la activa participación de las ciudades púnicas en los circuitos comerciales del Mediterráneo central y occidental. Pero el desembarco de Amílcar en Gadir y todos aquellos sucesos desencadenados ulteriormente que los historiadores grecolatinos relataron por escrito con mayor o menor fidelidad, y los historiadores posteriores hemos repetido una y otra vez, constituye una alteración trascendente en la evolución de éstas y de otras comunidades, pues Iberia, como antes lo había sido Sicilia, se convirtió en el escenario de las disputas entre potencias.

Sobre en la imagen del poder de la Iberia bárquida, surgen aspectos tan importantes, sobre los que pasaremos por encima, como la misma formación "helenística" de esta familia, en concreto de Aníbal, pues de hecho Sósilo de Lacedemonia había sido su maestro en letras griegas, y el cartaginés se acompañó de historiógrafos griegos en sus campañas como el mismo Sósilo o Sileno de Calacte. Otro aspecto no menor es el estudio de los mecanismos políticos por los que se pudo producir este fenómeno de convergencia ideológica, sobre todo si analizamos las relaciones de los cartagineses con el Egipto lágida, con las ciudades griegas de Sicilia, con la dinastía antigónida, de ahí el conocido tratado entre Aníbal y 
Filipo V de Macedonia, o con el seleúcida Antioco III (Lancel, 1997; Barceló, 2000).

Sin embargo, nos centraremos en algunas manifestaciones de la ideología helenística en la Península Ibérica introducidas por los Barca.

Como si de un reino helenístico se tratara, Cartago contraviniendo a su política más tradicional, conquistó un territorio extenso del sur y este de Iberia. Esto supuso la inclusión en sus dominios de un gran mosaico de etnias y formaciones políticas de Turdetania, Oretania y Contestania que se pretendían controlar desde ciudades fundadas expresamente para esta función: Akra Leuké, Kart-Hadast y otra fundación de nombre desconocido. Las razones de esta urbanización sistemática, como en otras partes del Mediterráneo, son en un primer momento esencialmente militares y administrativas. Como las dinastías antigónida, seleúcida y atálida, los Barca vieron en la creación de centros urbanos o la refundación de algunos existentes, quizás Carmo (Bendala, 1994: 64), el medio más eficaz de implantar una red administrativa necesaria para la cohesión del territorio. No dudarán tampoco en establecer relaciones matrimoniales con princesas indígenas y en utilizar las estructuras sociales (fides y pactos de hospitalidad) para asegurarse la fidelidad de las comunidades y el control del territorio. Asimismo, estos centros, como el caso de Kart-Hadast, recibieron contingentes de poblaciones extrajeras, como señala Polibio cuando la ciudad es conquistada por los romanos, y adquieren un carácter cosmopolita.

El caso de Cartago Nova es el mejor conocido por la descripción polibiana $(10,10,1)$, y por la documentación arqueológica que recientemente está saliendo a la luz (Martín y Roldán, 1991: 1824; Martín Camino, 1994: 320). Tanto una como otra dan idea de una capital que poco se diferencia de otras ciudades púnicas de influencia helenística. En primer lugar se fortifica con una muralla de casamatas, un tipo de fortificación realizado en función del extraordinario desarrollo de las técnicas poliorcéticas entre los siglos IV y III a.C. $\mathrm{Al}$ componente defensivo de este tipo de construcciones, se une un fuerte componente ideológico y propagandístico, presentando la imagen de una ciudad segura. El caso de Cartago Nova no es único; entre las ciudades de la órbita de Gadir se fortificaron de manera similar Doña Blanca (Barrionuevo y otros 1999; Ruiz Mata 1992) y Niebla (Pérez Macías y otros, 2000: 106-107), y también Carteia (Roldán y otros 1998).

Otro elemento de la fisonomía urbana de raíz helenística que se manifiesta en Cartago Nova es la edificación de un palacio en el llamado Arx
Asdrubalis, que según las más recientes investigaciones estuvo también relacionado con al menos tres edificios de función sacra en época republicana romana, uno dedicado a una divinidad salutífera, quizás Asclepios-Eshmun y otro a la diosa siria Atargatis (Pérez Ballester, 1998: 253 ss.). Este es otro fundamento ideológico propio de las monarquías helenísticas con un enorme significado propagandístico: la asociación de la dinastía, en este caso de una familia, a determinadas divinidades que actúan como protectoras. Citamos en este sentido la relación de los bárquidas con Melqart (González Wagner, 1999: 284) y el listado de dioses descrito en el tratado entre Filipo y Aníbal.

Otros aspectos que no abordaremos es la introducción de la moneda, que salvo los casos preexistentes de las cecas griegas de Emporion y Rhode y de Gadir, son un testimonio de las novedades introducidas por los bárquidas, constituyendo un fenómeno directamente relacionado con la guerra, con el pago de mercenarios y suministros, incorporado prontamente a la vida económica y política de numerosas comunidades de Iberia. Además la introducción de la moneda supuso el uso de determinadas iconografías imitadas de las prestigiosas monarquías helenísticas y de las cecas de Sicilia, que fueron copiadas a su vez por las incipientes emisiones hispanas (AAVV, 2000).

\section{Bibliografía}

AAVV (2000): Los cartagineses y la monetazión del Mediterráneo occidental. Anejos de AespA XXII. Madrid.

Altamira, R. (1909): Historia de España y de la civilización española I-II (segunda edición). Barcelona.

Arce, J. (1991): "García y Bellido y los comienzos de la Historia Antigua de España". Historiografía de la Arqueología y la Historia Antigua en España (siglos XVIII-XX), 209-211. Madrid.

Arteaga Matute, O. (1990): "La formación del mundo púnico". Historia de España, 456-469. Ed. Planeta. Barcelona.

Arteaga Matute, O. (1994): "La Liga Púnica Gaditana. Aproximación a una visión histórica occidental, para su contrastación con el desarrollo de la hegemonía cartaginesa, en el mundo mediterráneo". Cartago, Gadir, Ebusus y la influencia púnica en los territorios hispanos. VIII Jornadas de Arqueología feniciopúnica, 25-58. Ibiza.

Arteaga Matute, O. (2001): "La emergencia de la 'polis' en el mundo púnico occidental”, Protohistoria de la Península Ibérica, 217-281. Ed. Ariel. Barcelona. 
Ayerbe-Chaux, R. (1982): Historia de España. Alfonso X el Sabio. Antología. Madrid.

BARCELÓ, P. (1988): Kartago und die Iberische Halbinsel von der Barkiden. Studien zur kartagischen Präsen im westlichen Mittelmeerraum von der Gründung von Ebusus (VII Jh v. Chr.) bis zum übergang Hamilkars nach Hispanien (237 v. Chr.). Bonn.

Barceló, P. (2000): Aníbal de Cartago. Alianza Editorial. Madrid.

Barrionuevo, F.; Ruiz Mata, D. y Pérez, C. (1999): "Fortificaciones de casernas de Castillo de Doña Blanca (Puerto de Santa María, Cádiz)". Actas del II Seminario Internacional sobre temas fenicios, 47-55. Alicante.

Bendala Galán, M. (1982): "La perduración púnica en los tiempos romanos. El caso de Carmo". Huelva Arqueológica VI, 193-203.

Bendala GalÁn, M. (1987): "Los cartagineses en España”. Historia General de España y América, 115170. Ed. Rialp. Madrid.

Bendala Galán, M. (1994): "El influjo cartaginés en el interior de Andalucía". Cartago, Gadir, Ebusus y la influencia púnica en los territorios hispanos. VIII Jornadas de Arqueología fenicio-púnica, 59-74. Ibiza.

Blanco Freijeiro, A. (1967): "La colonización de la Península Ibérica en el primer milenio antes de Cristo". Las raíces de España, 167-197. Madrid.

BlázQuez Martínez, J.M. (1976): “Consideraciones históricas en torno a los supuestos retratos bárquidas en las monedas cartaginesas". Numisma 26, 39-48.

BLÁZQuez Martínez, J.M. (1980): “Colonización cartaginesa en la Península Ibérica”. Historia de España Antigua I. Protohistoria, 415-525. Ed. Cátedra. Madrid.

BlÁzQuez Martínez, J.M. (1991): "Los Bárquidas en la Península Ibérica”. Atti del II Congresso Internazionale di Studi Fenici e Punici, II, 27-50. Roma.

Cabrera de Córdoba, L. (1611): De historia, para entenderla y escrivirla. Madrid.

CÁssola, F. (1983): “Tendenze filopuniche e antipuniche in Roma”. Atti del I Congresso Internazionale di Studi Fenici e Punici, I, 35-59. Roma.

CATAlán, D. (1982): "La lenta "invención" de la Historia de España: el pueblo godo, como nación y como mito". Ensayo introductorio a R. Menéndez Pidal, Los españoles en la Historia. Madrid.

Cavanilles, A. (1860): Historia de España. Madrid.

Ciprés, P. y Cruz Andreotti, G. (1997): "El diseño de un espacio político: el ejemplo de la Península
Ibérica". Los límites de la tierra: el espacio geográfico en las culturas mediterráneas, 107-132. Madrid.

Cirujano, P.; Elorriaga, T. y Pérez, J. S. (1985): Historiografía y nacionalismo español 1834-1868. Madrid.

Costa, J. (1891-1895): Estudios ibéricos. Madrid.

Cruz Andreotti, G. (1987): "Un acercamiento historiográfico al Tartessos de Schulten”. Baetica 10, 227240 .

Cruz Andreotti, G. (1991): "Schulten y el 'carácter tartesio"”. Historiografía de la Arqueología y de la Historia Antigua en España (siglos XVIII-XX), 145-148. Madrid.

Cruz Andreotti, G. (1995): "La Península Ibérica en los límites de la Ecúmene: el caso de Tartesos”. Polis 7, 39-75.

Dubuisson, M. (1983): "Limage du carthaginois dans la littératue latine”. Studia Phoenicia, I-II, 156-166.

Ferrer Albeda, E. (1995): Los púnicos en Iberia. Análisis historiográfico y arqueológico de la presencia púnica en el sur de la Península Ibérica. Tesis doctoral inédita, Universidad de Sevilla.

Ferrer Albeda, E. (1996a): La España cartaginesa. Claves historiográficas para la historia de España. Universidad de Sevilla.

Ferrer Albeda, E. (1996b): "Los púnicos de Iberia y la historiografía grecolatina”. Spal 5, 115-131.

Ferrer Albeda, E. (1998): "Suplemento al mapa paleoetnológico de la Península Ibérica: los púnicos de Iberia”. RSF XXVI, 1, 31-54.

Ferrer Albeda, E. (2000): "Nam sunt feroces hoc libyphoenices loco: cilibiofenicios en Iberia?”. Spal 9, 421-433.

Ferrer Albeda, E. (2004): "Sustratos fenicios y adstratos púnicos. Los bástulos entre el Guadiana y el Guadalquivir". Huelva Arqueológica 20, 281-298.

Ferrer, E. y Prados, E. (2001-2002): “Bastetanos y bástulo-púnicos. Sobre la complejidad étnica del sureste de Iberia". Studia E. Cuadrado. AnMurcia, 16-17, 273-282.

Fontana, J. (1982): Historia. Análisis del pasado y proyecto social. Barcelona.

FORNER, J.P. (1816): Reflexiones sobre el modo de escribir la Historia de España. Madrid.

Frutos Reyes, G. DE (1991): Cartago y la política colonial. Los casos norteafricanos e hispano. Écija.

Frutos Reyes, G. DE (1993): “Aspectos de la presencia cartaginesa en la Península Ibérica durante el siglos V a.C.”. Actas del Coloquio de Historia Antigua de Andalucía I, 215-135. Córdoba. 
Gala Vela, C. (1988): "La figura de Aníbal en una historia española del siglo XVII". RSF XIV, 2, 229249.

García y Bellido, A. (1942a): Fenicios y cartagineses en Occidente. Madrid.

García y Bellido, A. (1942b): "Fenicios y cartagineses en España”. Sefarad 2. Madrid.

GARcíA Y BELlido, A. (1952): "La colonización cartaginesa desde sus comienzos (fundación de Ibiza, 654) hasta la conquista cartaginesa (237)". R. Menéndez Pidal (dir.), Historia de España. Protohistoria II, 337492. Madrid.

Godoy Alcántara, J. (1868): Historia crítica de los falsos cronicones. Madrid.

GonZÁlez Wagner, C. (1983): Fenicios y cartagineses en la Península Ibérica: Ensayo de interpretación fundamentado en un análisis de los factores internos. Madrid.

GonzÁlez Wagner, C. (1984): "El comercio púnico en el Mediterréno a la luz de una nueva interpretación de los tratados concluidos entre Cartago y Roma". MHA V, 211-224.

GonzÁlez Wagner, C. (1985): “Cartago y el Occidente. Una revisión crítica de la evidencia literaria arqueológica”. In memoriam Agustín Díaz Toledo, 437-460. Granada.

GonZÁlez Wagner, C. (1989): "The Cathaginians in ancient Spain: from administrative trade to territorial annexation". Punics Wars. Proceedings of the Conference help in Antwerp, 1988. Studi Phoenicia X, 145-156.

GonzÁlez Wagner, C. (1994): "El auge de Cartago (s. VI-V) y su manifestación en la Península Ibérica". Cartago, Gadir, Ebusus y la influencia púnica en los territorios hispanos. VIII Jornadas de Arqueología feniciopúnica, 7-24. Ibiza.

GonzÁlez WAGner, C. (1999): "Los Bárquidas y la conquista de la Península Ibérica”. Gerión 17, 263-294.

Guichot, J. (1969): Historia de Andalucía, I. Sevilla.

Hans, I.M. (1991): "L'immagine di Amilcare Barca presso i romani”. Atti del II Congresso Internazionale di Studi Fenici e Punici, I, 113-116.

Koch, M. (2002): "Cartago e Hispania anteriores a los Bárquidas”. Religión, lengua y cultura prerromanas de Hispania, 189-197. Salamanca.

Lafuente, M. (1850): Historia General de España desde los tiempos más remotos hasta nuestros días, I. Madrid.

LANCEL, S. (1997): Aníbal. Ed. Crítica. Barcelona.

López Castro, J.L. (1991a): “Cartago y la Península Ibérica cimperialismo o hegemonía?”. La caída de
Tiro y el auge de cartago. Trabajos del MAI 25, 73-86. Ibiza.

LÓPEz CASTRO, J.L. (1991b): "El imperialismo cartaginés y las ciudades fenicias de la Península Ibérica entre los siglos VI-III a.C.”. Studi di Egittologia e di Antichitá Puniche 9, 87-107.

López Castro, J.L. (1992): "Fenicios y cartagineses en el Extremo Occidente: algunas cuestiones terminológicas y de periodización". Homenaje a la Profesora Elena Pezzi, 343-348. Granada.

López Castro, J.L. (1994): “Cartago y la Península Ibérica en las historiografía española reciente (19801992)”. Hispania Antiqua XVIII, II, 519-532.

López Castro, J.L. (1995): Hispania Poena. Los fenicios en la Hispania romana. Barcelona.

López Castro, J.L. y Mora, B. (2002): “Malaka y las ciudades fenicias en el occidente mediterráneo. Siglos VI a.C. - I d.C.”. Colonizadores e indígenas en la Península Ibérica. Mainake XXIV, 181-214.

López PARdo, F. (2002): “Traslados de población entre el Norte de África y el sur de la Península Ibérica en los contextos coloniales fenicio y púnico". Gerión 20, 1, 113-152.

Martín Ruiz, J.A. (1995): Catálogo documental de los fenicios en Andalucía. Sevilla.

Maravall, J.A. (1972): "Mentalidad burguesa e idea de la Historia en el siglo XVIII". Revista de Occidente 107, 250-286.

Martín Camino, M. (1994): “Colonización fenicia y presencia púnica en Murcia”. El mundo púnico. Historia, sociedad y cultura, 293-324.

López Castro, J.L. y Roldán, B. (1991): "Púnicos en Cartagena". Revista de Arqueología 124, 18-24.

Masdeu, F. DE (1785): Historia Crítica de España y la cultura española II. Madrid.

Mayans i Siscar, A. (1742): Censura de Historia Fabulosas, obra posthuma de D. Nicolás de Antonio. Valencia.

MÉLIDA, J.R. (1929): Arqueología española. Ed. Labor. Barcelona.

Mestre Sanchís, A. (1988): "Conciencia histórica e historiografía”. Historia de España Menéndez Pidal, XXXI, 1, 301-345. Madrid.

Morales Santiesteban, J. (1838): “España cartaginesa y romana (1)”. Revista de Madrid I, 349 ss. Madrid.

Moreno Alonso, M. (1979): Historiografía romántica española. Introducción al estudio de la historia del siglo $X I X$. Sevilla.

Olmos Romera, R. (1991): “A. Schulten y la historiografía sobre Tartessos en la primer mitad del siglo XX". 
Historiografía de la Arqueología y de la Historia Antigua en España (siglos XVIII-XX), 135-144. Madrid.

Orcastegui, C. y SARASA, E. (1991): La Historia en la Edad Media. Ed. Cátedra. Madrid.

Ortiz y SANZ, J. (1795-1808): Compendio cronológico de la Historia de España desde los tiempos más remotos hasta nuestros días. Madrid.

Pérez Ballester, J. (1998): "El portvs de Cartago Nova. Sociedad y comercio tardo-helenísticos". III Jornadas de Arqueología Subacuática. Puertos antiguos y comercio marítimo, 249-261. Valencia.

Pérez Macías, J.A.; Campos, J. y Gómez Toscano, F. (2000): "Niebla, de oppidum a Madina". AAC 11, 91-122.

Pliego VÁzQuez, R. (2001): La circulación monetaria prerromana en el área de El Gandul. Memoria de Licenciatura inédita, Universidad de Sevilla.

Pliego VÁzQuez, R. (2003): "Sobre el reclutamiento de mercenarios turdetanos. El campamento cartaginés de El Gandul (Alcalá de Guadaíra, Sevilla)". Habis 34, 39-56.

Pliego VÁzQuez, R. (e.p.): "Un campamento cartaginés del siglo IV a.C. en El Gandul (Alcalá de Guadaíra, Sevilla)". RSF.

Rodríguez Mohedano, F.P. Y F.R. (1766): Historia Literaria de España. Madrid.

Roldán, L.; Bendala, M.; Blánquez, J. y Martínez Lillo, S. (1998): Carteia. Madrid.

Ruiz MatA, D. (1992): "La colonización fenicia en la bahía de Cádiz a través del Castillo de Doña Blanca". AAA 1990 II, 291-3000.

SÁnchez, F. y CRUZ Andreotti, G. (1988): "A. Schulten y los etruscos". Homenaje al Prof. Marcelo Vigil. Studia Historica VI, 27-35.

Schulten, A. (1920): Hispania. Barcelona.

Schulten, A. (1924a): "Tartessos. Contribución a la historia más antigua de Occidente". Revista de Occidente. Madrid.

Schulten, A. (1924b): "Tartessos". Boletín de la Real Academia de Ciencias, Bellas Letras y Nobles Artes de Córdoba 7, enero-marzo, 5-28.

Schulten, A. Y Bosch Gimpera, P. (1922): Fontes Hispaniae Antiquae I. Barcelona.

TAte, R.B. (1970): "El Paralipomenon de Joan Margarit, cardenal obispo de Gerona". Ensayos sobre la historiografía española del siglo XV. Madrid.

UlloA, M. DE (1796): Tratado de Cronología para la Historia de España. Memorias de la Real Academia de la Historia II. Madrid.

VIVES y ESCUDERO, A. (1917): Estudio de arqueología cartaginesa. La necrópoli de Ibiza. Madrid.

WhitTaker, C.R. (1978): "Carthaginian imperialism in the fifth and fourth centuries". Imperialism in Ancient World, 59-90. Cambridge.

WulfF Alonso, F. (1992): "Andalucía antigua en la historiografía española (siglos XVI-XIX)". Ariadna 10, 8-32. 